\title{
A NECESSIDADE DE INCLUSÃO DE UMA AGENDA PLURAL PARA PROMOVER A PARCERIA ESTADO-SOCIEDADE NA INTEGRAÇÃO ECONÔMICA NO MERCOSUL
}

\section{LA NECESIDAD DE INCLUSIÓN DE UNA AGENDA PLURAL PARA PROMOVER LA COOPERACIÓN ESTADO-SOCIEDAD EN LA INTEGRACIÓN ECONÓMICA EN EL MERCOSUR}

Mayra Thais Andrade Antônio Carlos Ribeiro ${ }^{* *}$

Resumo: O presente artigo analisa a necessidade de haver o diálogo entre os Estados Membros e a sociedade na integração econômica regional do MERCOSUL, bloco criado no âmbito da América latina cujos Estados Membros em processo de redemocratização empenharam-se na cooperação para expandir suas economias e reduzir desigualdades internas. A pesquisa baseou-se no método dedutivo em que se realizou um trabalho documental e bibliográfico sobre o tema além de um levantamento das atividades, dinâmicas e normas emitidas pelos órgãos do bloco para a discussão dos impactos causados pelo seu caráter intergovernamental. Nas considerações finais verifica-se que o MERCOSUL deve continuar a expandir a sua agenda doméstica e externa a fim de abordar os aspectos econômicos, as questões sociais, culturais e outras plurais para solidificar sua integração e adquirir maior visibilidade no cenário global e proporcionar melhorias na condição de vida de sua sociedade.

Resumen: Este artículo analiza la necesidad de un dialogo entre los Estados $y$ de la sociedad en la integración económica regional del MERCOSUR, bloque creado dentro de la América Latina cuyos Estados miembros en el proceso de democratización han involucrado en la cooperación para expandir sus economías y reducir las desigualdades sociales. La investigación se basó en el método deductivo en el que ella se realizó un trabajo documental y bibliográfica sobre el tema, así como un estudio de

* Pontifícia Universidade Católica de Minas Gerais. E-mail: mayrathais@gmail.com

** Universidade Federal de Minas Gerais. E-mail: antonilos@gmail.com 
las actividades, dinámicas y normas emitidas por los órganos del bloque para discutir los impactos causados por su carácter intergubernamental. En las consideraciones finales, parece que el MERCOSUR debería seguir ampliando su agenda doméstica y extranjera para abordar los aspectos económicos, sociales, culturales y otros para consolidar su integración $y$ hacerse más visible en el escenario global y proporcionar mejoras en condiciones de vida de su sociedad.

Palavras-chave: Integração Econômica e Social, Nova Agenda, MERCOSUL

Palabras clave: Integración Económica y Social, Nueva Agenda, MERCOSUR

\section{INTRODUÇÃO}

Após a Nova Ordem que se instaurou no âmbito das relações internacionais pós Guerra Fria em 1989, a globalização tornou-se mais expressiva o que possibilitou a formação de redes de diálogos políticos, econômicos, comerciais, sociais e culturais entre Estados, instituições e indivíduos, e, por conseguinte, a integração econômica entre regiões internacionais. Assim, surge o Direito Econômico Internacional sendo um ramo da ciência jurídica é bastante influenciado pelas relações integracionistas de Estados, Organizações Internacionais e os indivíduos, que interferem em sociedades singulares para fins de comércio, para regulação das economias internas em consonância com as relações internacionais que os governos estabelecem.

No mesmo sentido, pelo estreitamento das relações internacionais, tem-se como uma de suas consequências a criação dos blocos econômicos de integração regional e, geralmente por questões geográficas, há a formação de blocos regionais que se dispõem a seguir o Direito Econômico Internacional e estabelecer as suas regras regionais para promover a circulação, proteção e manutenção das riquezas e investimentos políticos entre os membros do bloco para potencializar as suas economias e o comércio em função de maior visibilidade no âmbito do sistema internacional.

Para regular eharmonizar as relações entre os Estados em cooperação institui-se o Direito de Integração Econômica Regional, contendo normas e princípios específicos, para estruturar a nova ordem econômica internacional formada por Estados e blocos de integração regional, tendo como momento e formalidade máxima a união jurídico-política entre os membros através da consolidação do Direito Comunitário.

Insta salientar que a referida integração econômica é constituída por etapas, tendo início pela liberação comercial através da redução (com 
posterior eliminação) das tarifas protecionistas (Preferências Tarifárias e Livre Comércio) e evolui, paulatinamente, para o desenvolvimento de políticas macroeconômicas pela união comercial, econômica, jurídica e política (União aduaneira e Mercado Comum), sendo constituídos órgãos cujos Estados membros do bloco delegam competências supranacionais para que esses atuem de maneira específica junto aos interesses do bloco de maneira a criar direitos e obrigações aos seus tutelados (União econômica e monetária).

Junto a essa formação deredes econômicase comerciais estabeleceuse a Lex Mercatoria, a regulação das relações comerciais entre os Estados no processo de expansão comercial na corrida marítima da região europeia. Assim, tem-se que a Lex Mercatoria advém dos costumes dos indivíduos integrados na atividade de transação de mercado, e, a partir da consolidação dessa prática houve sua regulação normativa, visando conferir segurança a essa relação comercial. O referido instrumento jurídico pode ser definido como um conjunto de regras costumeiras baseadas na liberdade contratual aplicadas para resolver conflitos mercantilistas de maneira rápida e informal, não seguindo a lei nacional de nenhum Estado, sendo, portanto, transnacionais ${ }^{1}$, relacionadas ao comércio internacional.

A Relevância acerca dessa regulação trazida pela Lex Mercatoria referese à liberdade de autorregulação da atividade do comércio internacional por aqueles que atuam nesse mercado tornando-o mais dinâmico e adequado aos interesses dos envolvidos. Diante dos conflitos surgidos entre comerciantes a Lex Mercatoria possui extrema relevância em razão de sua orientação para dirimi-los em respeito aos contratos internacionais estabelecidos. Percebe-se, assim, o respeito à liberdade de instituição dos contratos comerciais internacionais e a aplicação das práticas internacionais do comércio segundo a vontade das partes negociantes.

Assim, no âmbito das regras do Direito Econômico Internacional os países estreitam suas relações evoluindo de meras cooperações para formarem institutos efetivos de integração visando não apenas o fortalecimento comercial, mas também reduzir as desigualdades sociais que assolam as populações.

Dentre os esforços da integração econômica entre países destacase a institucionalização da União Europeia e o MERCOSUL, este no âmbito da América do Sul. Este último foi criado em 26 de março de 1991 quando Argentina, Brasil, Paraguai e Uruguai tornaram-se signatários do Tratado de Assunção, para estreitar os laços políticos buscando o desenvolvimento econômico. Conforme o sistema de integração regional desse bloco estabeleceu-se um prazo de até o fim de 1994 para a efetivação do Mercado Comum entre os Estados Membros.

1 AZEVEDO, Pedro Pontes. "A Lex Mercatoria e sua aplicação no ordenamento jurídico brasileiro”. Revista Prima Facie. 2006, ano 5, n 9, p. 93-105. 
O presente artigo terá como foco a integração econômica regional no âmbito do MERCOSUL, que possui uma dinâmica de desenvolvimento peculiar, pois, conforme Silva ${ }^{2}$, o bloco encontra-se numa União Aduaneira imperfeita já que não há liberação completa do comércio pela falta de livre locomoção dos fatores de produção, como os serviços e os trabalhadores e não se implementou políticas econômicas comuns. Deste modo, propõe-se uma investigação sobre os pontos em que a União Aduaneira imperfeita, no caso do MERCOSUL, conseguiu avançar nos últimos anos de modo a favorecer seus membros sul-americanos.

\section{FORMAČ̃̃O DOS PRINCIPAIS BLOCOS ECONÔMICOS REGIONAIS NAS RELAÇÕES INTERNACIONAIS - O CASO EUROPEU E O SUL-AMERICANO}

Após a Segunda Guerra Mundial com as catástrofes das bombas nucleares e o cenário de terror que se instaurou pelo mundo houve o Início da jornada global de proteção da dignidade da pessoa, meio ambiente e o desenvolvimento econômico para além dos territórios nacionais. A partir de então as relações internacionais se tornaram mais dinâmicas, favorecendo o debate e a integração, rede de Estados, proporcionando a criação de instrumentos normativos e valores comuns entre os acordantes para dirimir as diferenças de desenvolvimento e melhorar as condições econômicas dos Estados e sociais de suas populações.

Para regular tais relações tem-se os fundamentos gerais do Direito Internacional como o pacta sunt servanda, no qual os acordos, Tratados, devem ser respeitados pelas partes que se obrigaram a cumpri-los; principio da boa-fé, que se refere ao respeito, à confiança entre as partes envolvidas em um contrato; e legalidade, pelo qual as acordos devem corresponder à validade das leis e o respeito ao seu texto.

Sobre o início da integração econômica regional, tendo como principal expoente a formação da União europeia, percebese o sentimento de união das sociedades em prol da reconstrução do continente que estava alastrado em virtude das consequências catastróficas que se seguiram no período das duas Grandes Guerras Mundiais. Após os acontecimentos desumanos que desestruturaram os Estados europeus, tanto nos aspectos políticos, econômicos e culturais, em meio aos esforços para o auxilio as desenvolvimento europeu. Neste momento pós-guerra, os Estados se uniram no intuito de reconstruir a Europa, primeiramente, em seus aspectos econômicos, propondo, desta forma, uma integração comercial. Houve a criação do BENELUX ${ }^{3}$ em 1944, formado pelos Estados da Bélgica, Holanda e Luxemburgo, cujos

2 SILVA, Roberto Luiz. Direito Internacional Público. $4^{\text {a }}$ ed. Belo Horizonte, Del Rey, 2010.

3 Sigla formada pelas letras iniciais dos Estados integrantes do bloco, formado por Bélgica, Holanda e Luxemburgo. 
objetivos incluem união aduaneira entre os acordantes, principalmente sobre os insumos de ferro, carvão e aço. Os Países que antes eram inimigos de guerra uniram-se com o ideal de desenvolver suas economias inicialmente baseadas no Ferro, Carvão e Aço.

Momentos posteriores houve uma proposta de reconstrução do continente, feita por Winston Churchill em 1946, na universidade de Zurique. Nesta ocasião Churchill propôs a formação de um Conselho da Europa. Tal ideia fomentada por Churchill foi o lócus da criação da Comunidade Europeia do Carvão e do Aço (CECA), com inspiração do governo francês.

Junto aos esforços dos Estados Europeus os Estados Unidos da América (EUA) através de seu secretário de Estado George Marshall, estabeleceu-se formalmente em 15 de Julho de 1947 o programa para a recuperação da Europa, o Plano Marshall, patrocinado pelos EUA de forte inspiração liberal ${ }^{4}$, cujas negociações impulsionaram a posterior criação de diversos organismos internacionais, tais como: Banco Internacional para Reconstrução e Desenvolvimento (BIRD) em 1944, com objetivo inicial de auxiliar na reconstrução da Europa e posteriormente reduzir a pobreza com assistência financeira aos países necessitados; Fundo Monetário Internacional (FMI) em 1944, para equilibrar a taxa de cambio e balanço de pagamentos do sistema financeiro internacional; Organização das Nações Unidas (ONU) em 1945, para criar o espaço de diálogo com órgãos decisórios, normativos, jurídicos e deter os conflitos que ameacem a paz e segurança coletiva; Acordo Geral de Tarifas e Comércio (GATT) em 1947, para favorecer o livre comércio entre os países com normas internacionais (substituído pela OMC em 1995) e; Formar a Comunidade Europeia.

Percebe-se que foram lançadas as bases da integração econômica internacional bem como da solidariedade internacional para reconstruir cidades e Estados visando o desenvolvimento de suas potencialidades para que tivessem condições mínimas de participação na concorrência global a partir da dinâmica de liberalização comercial.

Em 1951 foi criada a Comunidade Europeia do Carvão e do Aço (CECA) composta por Alemanha, Itália, França, além de Bélgica, Holanda e Luxemburgo (do bloco também de cooperação econômica BENELUX), cujos objetivos eram de alcançar a paz e reconciliação entre Estados europeus inimigos de guerra, surgindo, desta forma, os fundamentos para criação de um Direito Comunitário na região europeia. A natureza jurídica da comunidade europeia foi definida no artigo $6^{\circ}$ da CECA, sendo classificada como pessoa jurídica de Direito Internacional.

Nos anos de 1958 os Tratados de Roma deram resultado à Comunidade Econômica Europeia (CEE) e a Comunidade Europeia

4 CARNEIRO, Cynthia Soares. Para Entender o Direito da integração regional. Belo Horizonte: Del Rey, 2007. 
da Energia Atômica (Euratom) para criar uma área de união aduaneira com livre comércio, sem tarifas aduaneiras, além de estabelecerem taxas comuns para importação/exportação no bloco.

Ressalta-se que o termo União Europeia foi utilizado a princípio pelos chefes de Estados e de Governo dos Estados-membros das organizações europeias na Conferencia de Paris de 1972, cujo objetivo era transformar as finalidades dos tratados já aderidos numa efetiva união européia. A unificação institucional europeia consolidou-se por meio do Ato Único Europeu, instituído em 1986, que reforçou a dinâmica da integração econômica no bloco junto aos princípios de Direito Comunitário, à medida que melhorou o processo decisório dos órgãos do bloco por definiu a sua organização e unificação institucional baseada no principio da subsidiariedade, pois se delegou competências específicas sobre a integração comunitária da UE aos seus órgãos e conforme o principio da proporcionalidade os órgãos deverão atuar na medida de suas competências para que o Direito emitido por eles seja respeitado e aplicado pelos os Estados e demais sujeitos de direitos ${ }^{5}$.

Com a vigência do Tratado de Maastricht em 1992 instituiu formalmente o Direito Comunitário que estava em prática na União Europeia abrangendo temas não somente econômicos, mas também Direitos Humanos, Direito Eleitoral, Direitos Trabalhistas, Direitos do Consumidor, Direito Ambiental entre outros. O Direito Comunitário é autônomo por não depender das Constituições nacionais de cada país, possui aplicação imediata e superior aos países, pois tal Direito é criado pelos órgãos da própria União Europeia que elaboram as leis, executam e julgam sobre os temas específicos à integração regional que existe no bloco europeu e suas relações internacionais.

Os principais órgãos da União Europeia que atuam de maneira a aproximar os sujeitos de direito da integração regional europeia em benefício de sua a economia, política, sociedade e cultura do bloco são: o Conselho Europeu que profere as orientações políticas e define as prioridades da UE; o Parlamento Europeu que representa os povos da comunidade europeia e seus parlamentares nacionais atuando conforme o Estado Democrático de Direito em respeito à cidadania no bloco; a Comissão Europeia responsável pelas relações políticas, comerciais internacionais e por apresentar propostas de legislação, além de fiscalizar os tratados comunitários; o Conselho da União Europeia formado por representantes dos governos pelos Ministros que se reúnem para tratar das diretrizes da UE através de temas como economia, finanças e negócios estrangeiros; o Tribunal de Primeira Instância, que possui competência para julgar recursos e ações propostas por pessoas físicas e jurídicas contra

5 CAMPOS, João Mota de e CAMPOS, João Luiz Mota de. Manual de Direito Comunitário - O Sistema Institucional. A Ordem Jurídica. O Ordenamento Económico da União Europeia. Coimbra: Coimbra, 2007. 
as decisões das instituições comunitárias; o Tribunal da Função Pública, constituído para a solução de conflitos trabalhistas; o Tribunal de Justiça da União Europeia responsável por julgar situações de conflito sobre a aplicação das normas do Direito Comunitário especificamente.

Salienta-se que os conceitos de supranacionalidade e de organismo intergovernamental, também são peculiares ao Direito comunitário formado em razão do estreitamento da integração econômica europeia. O primeiro conceito é parte dos seus mecanismos de integração, tendo como base o reconhecimento pelos Estados dessa supranacionalidade que consiste na existência de valores ou interesses comuns, estrutura institucional posta a serviço dos objetivos comuns e autonomia. No que se refere ao conceito de organismo intergovernamental, os Estadospartes conservam sua autonomia plenamente, de forma que os Tratados e convenções por eles celebrados não podem impor aos mesmos qualquer forma de submissão a outro órgão ${ }^{6}$.

Em 1998 estabeleceu-se a Zona Euro, com a elaboração de políticas monetárias unificadas, sendo o Euro a principal moeda a ser utilizada no âmbito das transações comerciais (nacionais e internacionais) da UE. Um dos resultados institucionais dessa política unificada foi a criação do Banco Central Europeu que atua para garantir a estabilidade dos preços dentro da Zona Euro auxiliando os 19 países ${ }^{7}$ que adotaram o Euro a terem sua economia e sistema financeiro equilibrado. Atualmente para que um país participe do bloco deve adotar o Euro como moeda exclusiva.

Por fim à sequência de Tratados comunitários europeus, tem-se o Tratado de Lisboa assinado pelos Estados em 2007, através do qual se modificou os Tratados anteriores, conferindo personalidade jurídica a União Europeia e atuação supranacional junto à organização dos Estados. Pelo Tratado de Lisboa as Comunidades Europeias foram superadas pela sucessão da instituição da União Europeia. Pelo Tratado de Lisboa tornou-se mais clara as competências da União Europeia e traz reforço ao Parlamento Europeu, por uma União Europeia mais democrática que represente seus cidadãos dos 27 países do bloco.

Outros blocos de integração econômica regional foram criados em diferentes regiões do mundo por objetivos comuns aos Estados Membros, a fim de proporcionar o desenvolvimento interno de cada país e favorecer a expansão do bloco. Fora do contexto territorial europeu, mas no mesmo sentimento de integração dos povos em circunstâncias de conflitos governamentais, tem-se a figura de Simón Bolívar, líder do movimento separatista das colônias espanholas de sua metrópole

6 FARIA, Adriana Spagnol de. "Soberania popular e a supranacionalidade no MERCOSUL". [Dissertação de mestrado]. Pontifícia Universidade Católica de Minas Gerais. Belo Horizonte, 2004. 7 Países que adotaram o Euro: Alemanha, Áustria, Bélgica, Chipre, Eslováquia, Eslovênia, Espanha, Estônia, Finlândia, França, Grécia, Irlanda, Itália, Letônia, Lituânia, Luxemburgo, Malta, Países Baixos, Portugal. Países que não adotaram o euro: Bulgária, Croácia, Dinamarca, Hungria, Polônia, República Checa, Reino Unido, Romênia e Suécia. 
Europeia. Em 1815 Simón Bolívar escreveu a "Carta da Jamaica” em que estavam presentes seus desejos de liberdade latino-americana frente ao domínio sofrido no sistema colonial, “(...) e o 'libertador' manifestou os referidos anseios no Congresso Anfictiônico do Panamá, instalado em 22 de junho de $1826 "$ ".

Apesar de não ter prosperado o ideal de Bolívar em promover a completa integração Latino-Americana, o progresso integracionista se desenvolveu na medida em que os Estados sul-americanos buscavam a cooperação para expandir seus domínios políticos, econômicos e melhorar as condições sociais das culturas envolvidas nesses processos regionais.

$\mathrm{Na}$ década de 60 do século XX foi criada a Associação Latinoamericana de Livre Comércio (ALALC) por meio do Tratado de Montevidéu (TM-60), para que fosse instituída uma zona de livre comércio entre Argentina, Bolívia, Brasil, Chile, Colômbia, Equador, México, Paraguai, Peru, Uruguai e Venezuela. Contudo, a ALALC não foi bem sucedida devido aos conflitos políticos internos que sofriam alguns Estados naquele período. Outro bloco criado em âmbito sul-americano foi a Associação Latino-Americana de Integração (ALADI), em 1980, cujos objetivos eram pautados em benefícios políticos e econômicos, como preferências tarifárias e descontos comerciais.

Em 1988 foi assinado o Tratado de Integração Cooperação e Desenvolvimento, entre os Estados Brasil e Argentina para estabelecerem um mercado comum pela eliminação das tarifas alfandegárias. Em meio à evolução das relações oriundas dos acordos bilaterais entre Brasil e Argentina, que estavam em estágio político de redemocratização de seus governos após passarem pelo período de ditaduras militares, os Estados do Paraguai e Uruguai requereram a inclusão nesta integração, por perceberem a oportunidade de estreitar os laços políticos buscando o desenvolvimento econômico ao se unirem em um bloco.

Deste modo, em 26 de março de 1991 foi instituído o Mercado Comum do Sul (MERCOSUL) pela assinatura do Tratado de Assunção (TA). Conforme o sistema de integração regional desse bloco estabeleceu-se um prazo de até o fim de 1994 para a efetivação do mercado comum entre as partes, sendo este um dos projetos mais auspiciosos de cooperação regional.

O sistema do bloco foi fundamentado para promover a integração econômica mercantil, a União Aduaneira, status que possui algumas características, para posteriormente progredir para um Mercado Comum, objetivo ainda a ser realizado. A União Aduaneira entre Estados Membros de um bloco de integração é caracterizada pelas preferências tarifárias (tarifas reduzidas nos produtos dos Estados

8 SOARES, Mário. “Teoria geral da cidadania em suas expressões clássicas - Paradigma Greco-romano e medieval”. [Dissertação de mestrado]. Faculdade de Direito da Universidade Federal de Minas Gerais. Belo Horizonte, 1995. 
Membros que circulam no bloco), o livre comércio (ausência de barreiras alfandegárias) e a adoção de uma Tarifa Externa Comum (TEC) através da qual o produto que entrar no território do MERCOSUL terá o mesmo valor de importação/exportação para todos os integrantes do bloco ${ }^{9}$.

Atualmente são Estados Associados Bolívia, Chile, Colômbia, Equador, Guiana, Peru e Suriname, assim objetivam a participação na zona de livre comércio, porquanto ainda não possuem status de membro do bloco. A Venezuela aderiu ao bloco como membro associado em 2006 e desde então aguardava apenas a aprovação do Paraguai, mas tornou-se membro oficial em agosto 2012, após suspensão do Paraguai do MERCOSUL pelas declarações dos demais Estados Membros de que houve um golpe político para depor o Presidente do Paraguai o que viola os princípios democráticos já consagrados no Protocolo de Ushuaia do bloco em 1998. No próximo tópico se discutirá a atuação e dinâmica do MERCOSUL no seu processo de integração econômica regional.

\section{A ATUACCÃO INTERGOVERNAMENTAL DO MERCOSUL NO CENÁRIO DAA INTEGRAÇÃO}

O sistema do bloco MERCOSUL foi fundamentado para promover a integração econômica mercantil, a união aduaneira. Novos órgãos de integração regional do bloco foram instituídos pelo Protocolo de Ouro Preto (POP) de 1994 e a principal estrutura institucional do bloco apresenta-se da seguinte forma: Conselho do Mercado Comum (CMC), órgão político e principal normativo, exerce a titularidade jurídica do MERCOSUL; Grupo Mercado Comum (GMC) participa da produção do direito de integração, elaborando projetos normativos que serão submetidos ao Conselho; Comissão de Comércio do MERCOSUL (CCM), com atribuições normativas específicas para o comércio; Foro Consultivo Econômico-Social (FCES); Secretaria Administrativa do MERCOSUL (SAM); e o atual Parlamento do MERCOSUL (Parlasul), que substituiu a Comissão Parlamentar Conjunta (CPC), criado em 06 de dezembro de 2006, em Brasília, representa os interesses da sociedade civil dos países membros do bloco.

Completando a estrutura institucional do MERCOSUL há ainda organizações de integração responsáveis por interpretar e aplicar suas normas, tendo como diretrizes os princípios do processo de integração regional do bloco. Essa função é realizada pelos tribunais do MERCOSUL, sendo os Tribunais Ad Hoc, constituídos árbitros escolhidos pelos Estados litigantes para dirimir os conflitos entre si e o Tribunal Permanente de Revisão (TPR), constituído pelo Protocolo de Olivos em 18 de fevereiro de 2002, competente para julgar recursos de revisão advindos de um tribunal Ad Hoc. O TPR demonstra o que

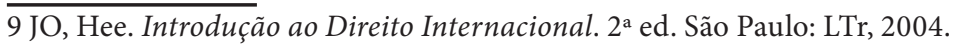


grande parte dos pesquisadores afirmam quanto à necessidade de construção jurisprudencial, pois representa um avanço na consecução de uma estrutura jurídico-institucional firme no bloco ${ }^{10}$.

Ressalta-se que os órgãos decisórios são de caráter intergovernamental o que cria dependência funcional daqueles, pois devem atuar em conformidade ao que determinam os Estados membros dependo do crivo desses para que o direito produzido pelos órgãos seja incorporado aos ordenamentos internos, contrário ao que ocorre na União Europeia, pois o Direito da União Europeia possui aplicação direta e incorporação imediata aos países membros.

A estrutura intergovernamental foi escolhida pelo MERCOSUL para reduzir as assimetrias e tornar compatível a cooperação mútua junto à expansão internacional do bloco com vistas à consolidação de um mercado comum do Cone Sul, englobando a integração social e cultural, junto à econômica-política. Ressalta-se que o contexto no qual o MERCOSUL foi criado era distinto da UE, pois os governos sulinos basearam-se no desenvolvimentismo interno e da sua região, como alternativa de autodeterminação em face dos ditames da economia neoliberal que beneficiara as estruturas econômicas dos países que possuíam maiores reservas financeiras, ou seja, as grandes potências mundiais.

A maior parte dos Estados Membros do MERCOSUL expressou em suas Constituições a importância da integração regional sul-americana e outros, como Argentina e Paraguai, ainda reconhece a possibilidade de criação de órgãos supranacionais. Sobre este aspecto discorre ${ }^{11}$ :

É importante que haja o reconhecimento e aprovação da integração pelo ordenamento jurídico interno dos Estados integrantes do MERCOSUL, de outra maneira tal união seria infrutífera e ineficaz para a evolução das negociações extra-bloco e dos direitos e garantias conferidos aos seus destinatários.

Conforme as disposições sobre os órgãos do bloco, trazidas no art. $2^{\circ}$ do Protocolo de Ouro Preto (POP) assinado em 1994, os órgãos do MERCOSUL possuem natureza intergovernamental. Assim, àqueles não foi concedida competência superior ou a soberania partilhada com os Estados ${ }^{12}$,

10 MÜLLER, Vivian Cristina. "Direito comunitário: a função judicial no MERCOSUL" [online]. Jus Navigandi. 2004, ano 9, n 232 [acesso em 08 nov. 2014]. Disponível em: <http:// jus.com.br/revista/texto/4873>

11 ANDRADE, Isabela Piacentini de. "MERCOSUL e desenvolvimento? Integração regional e desenvolvimento". In BARRAL, Welber e BACELLAR FILHO, Romeu Felipe (ed.). Florianópolis: Fundação Boiteux, 2007, p. 8.

12 Sobre este aspecto Baracho afirma que o princípio que fundamenta a estrutura dos órgãos de integração regional é o da subsidiariedade, segundo o qual os Estados Membros delegam competências aos organismos comunitários com vistas a realizarem os objetivos definidos no plano de consolidação da integração de maneira mais eficaz, quando a ação dos próprios Estados isoladamente for insuficiente. Conferir mais em: BARACHO, José Alfredo de Oliveira. 
mas sim atuam em conjunto aos Poderes Nacionais como o Legislativo, o Executivo e o Judiciário, para promoverem a aproximação entre o direito de integração existente no MERCOSUL e o interno dos Estados.

Há discussão doutrinária sobre a eficácia da atuação dos órgãos mercosulinos. Autores afirmam que as decisões políticas estão eivadas de interesses nacionais que obstam a expansão do interesse regional o que faz com que os órgãos do bloco não atuem de forma coesa. Seguem tal argumento Everts, Almeida, Guerra e Ferreira ${ }^{13}$ :

Conforme Ventura ${ }^{14}$ deveria haver um órgão jurisdicional supranacional mercosulino para garantir a eficácia de suas decisões, seguem esse entendimento autores como Silva ${ }^{15}$.

Outros afirmam que para haver maior segurança jurídica e credibilidade na atuação dos órgãos mercosulinos é preciso que esses ajam em benefício do direito de integração regional criado pelo bloco e os interesses em se desenvolver a região. Assim, descartam a necessidade de dotar os órgãos do MERCOSUL com competências supranacionais, vez que até mesmo tal estrutura regional não garante a consolidação da integração e nem seu aprofundamento, mas contribui para dar maior responsabilidade de decisões aos órgãos, senão vejamos:

Não há uma relação direta $a$ priori entre instituições supranacionais e efetividade. Por si só, a introdução, no arcabouço jurídico institucional de um processo de integração, de elementos tradicionalmente associados ao conceito de supranacionalidade não assegura a consecução dos objetivos atribuídos à organização ou o adequado cumprimento das decisões adotadas nesse âmbito. Por outro lado, nada impede que, na ausência desses elementos, as instituições possam criar uma efetiva integração entre seus membros e gerar, naturalmente uma demanda por maior integração, graças à capacidade de defesa e promoção dos interesses de seus integrantes ${ }^{16}$.

O princípio de subsidiariedade: conceito e evolução. Rio de Janeiro: Forense, 1997.

13 EVERTS, Philip. "Democracy and foreign policy". In: CASTERMAS-HOLLEMANP, Monique; HOOF, Fried Van; SMITH, Jaqueline. The role of the nation-estate in the 21st century: human rights, international organizations and foreign policy. The Hague: Cambridge, 1998; ALMEIDA, Paulo Roberto. Dilemas da soberania do MERCOSUL: a soberania. Rio de Janeiro: Renovar, 1999; GUERRA, Sidney Cesar Silva. "Os desafios à integração regional no âmbito do MERCOSUL”. Revista de Direito da UNIGRANRIO. 2009, vol 3, p. 1-26; FERREIRA, Thiago José Milet Cavalcanti. "Efeito direto das normas comunitárias: Um ensaio sobre o futuro da experiência brasileira" [online]. Jus Navigandi. 2009, ano 13, n 2139 [acesso em 02 dez. 2014]. Disponível em: <http://jus.com.br/artigos/12807/efeito-direto-das-normas-comunitarias>

14 VENTURA, Deisy F. L. "Os dilemas da institucionalização: um turning point para o MERCOSUL”. São Paulo em Perspectiva. 1995, vol 9, n 1, p. 75-79.

15 SILVA, Renata Cristina de Oliveira Alencar; SILVA, Osvaldo Alencar. "Supranacionalidade e integração: o caso MERCOSUL” [online]. Jus Navigandi. 2003, ano 7, n 64 [acesso em 08 nov. 2014]. Disponível em: <http://jus.com.br/artigos/3985/supranacionalidade-e-integracao/1> 16 CARVALHO, José Antônio Marcondes de; BENJAMIN, Daniela. "Supranacionalidade ou efetividade: a dimensão jurídico-institucional do MERCOSUL”. In: Seminário MERCOSUL 15 anos: Avaliação e perspectivas (março de 2006). São Paulo: s.n., 2006, p. 20. 
(...) o que importa é o fato de termos, ou não, instituições comunitárias que garantam a concretização desses princípios gerais [do Direito Comunitário]. Ou seja, é preciso auferir se as instituições mercosulinas tem sido capazes de exercer controle eficaz sobre a aplicação do direito gerado no bloco regional ${ }^{17}$.

Anselmo, Silva e Silva, e Costa e Silva ${ }^{18}$, dispõem que para haver uma atuação dinâmica e eficaz dos órgãos do MERCOSUL é necessário o consenso entre o poder nacional e as competências atribuídas àqueles para que se possa então transferir prerrogativas inerentes às jurisdições nacionais para os órgãos de integração econômica regional.

Os Estados Membros do MERCOSUL possuem significativa influência e força por sua integração, observadas e ressalvadas as dificuldades econômicas e a desigualdade social percebida, pois aqueles se enquadram nos aspectos caracterizadores de Estados em desenvolvimento (antes nomeados de $3^{\circ}$ Mundo). Conforme Silva ${ }^{19}$ afirma: "O Tratado de Assunção está imbuído de uma visão neoliberal de integração, onde a criação de comércio e a especialização são metas principais para o processo (da retomada do crescimento e desenvolvimento econômico da região)".

Através da criação do MERCOSUL os governos viram a possibilidade de solução das suas necessidades econômicas e políticas, bem como a ampliação dos mercados nacionais pelo aproveitamento pleno dos seus recursos disponíveis, preservação ambiental, melhora das relações entre os Estados e coordenação de políticas macroeconômicas, ou seja, realizar transações de investimentos globais para o bloco.

Os objetivos registrados no Tratado de Assunção são: a livre circulação de bens, serviços e fatores produtivos pela eliminação dos direitos alfandegários e restrições não tarifárias à circulação de mercadorias e de qualquer outra equivalente; o estabelecimento de uma tarifa externa comum; adotar políticas comerciais junto a terceiros Estados; a coordenação de políticas macroeconômicas e setoriais (agrícola industrial, fiscal, monetária, cambial e de capitais, comunicação, entre outras acordadas) entre os Estados-membros junto ao comércio exterior para assegurar condições adequadas de concorrência entre os

17 CARNEIRO, Cynthia Soares. Para Entender o Direito da integração regional. Belo Horizonte: Del Rey, 2007, p. 128.

18 ANSELMO, José Roberto. “O MERCOSUL sob a ótica do direito comunitário”. Revista do Instituto de Pesquisas e Estudos. 2000, no 29, p. 149-160; SILVA, Renata Cristina de Oliveira Alencar; SILVA, Osvaldo Alencar. "Supranacionalidade e integração: o caso MERCOSUL" [online]. Jus Navigandi. 2003, ano 7, n 64 [acesso em 08 nov. 2014]. Disponível em: <http:// jus.com.br/artigos/3985/supranacionalidade-e-integracao/1>; COSTA E SILVA, Danielle Cristine. "Soberania e MERCOSUL. [Dissertação de mestrado]. Pontifícia Universidade Católica de Minas Gerais. Belo Horizonte, 2003.

19 SILVA, Roberto Luiz. Direito Econômico Internacional e Direito Comunitário. Belo Horizonte: Del Rey, 1995, p. 235. 
membros do MERCOSUL, além de harmonização legislativa nas áreas pertinentes com vistas a fortalecer o desenvolvimento da integração regional; e reciprocidade de direitos e obrigações entre os membros e compromisso em manter os tratados já concluídos pela ALADI.

No que se refere aos aspectos econômicos e tributários do Tratado de Assunção, tem-se a redução das tarifas alfandegárias e suas implicações nas relações entre os Estados-membros. Através do MERCOSUL as partes gozam de uma de uma Preferência Tarifaria ou Margem em Preferência na Zona Comum, onde as importações terão livre tráfego. Essa margem de preferência, em que as tarifas são reduzidas para os membros do bloco lhes é atraente e auxilia a concretização da integração. Sobre a criação de uma Tarifa Externa Comum (TEC), criada em 1994, conforme o autor supracitado significa que os Estados Membros deverão ter a mesma alíquota tarifária sobre os produtos adquiridos nos Estados que não são partes do bloco nas relações de importação e exportação.

Explica Leal ${ }^{20}$ explica sobre a relevância da coordenação das políticas macroeconômicas comuns, vez que essas transações caso sejam feitas individualmente por cada Estado, não beneficiará aos demais membros do bloco, o que desvia, dessa forma, dos objetivos integracionistas comuns. São elementos dessas relações macroeconômicas: a política cambial, que envolve a variação das taxas de câmbio da moeda nacional em relação à outra moeda padrão; a política monetária concernente às taxas de juros e quantidade de moeda a ser emitida; e a política fiscal, como a gestão e fiscalização dos recursos a serem arrecadados e gastos pelo Estado.

A integração econômica é o primeiro aspecto que estreitamento das relações entre países que deve ser formalizado e estruturado junto a criação de órgãos imbuídos de atuar de modo a dialogar com os governos e harmonizar as relações entre eles para que os fins de integração concretizem, fins estes que são bem observados por José Eduardo Faria, vejamos:

[A Integração Regional é] estratégia especialmente concebida para viabilizar a obtenção de melhores condições de participação no intercâmbio mundial, maximizar o aumento das economias de escala, minimizar os custos sociais e econômicos da globalização e propiciar uma defesa minimamente eficaz contra a especulação financeira e os fluxos de capitais não-produtivos ${ }^{21}$.

O MERCOSUL avançou em termos de integração econômica nos últimos anos em que pese não ser se concretizado totalmente a liberalização de produtos, serviços e trânsito de pessoas, visto que

20 LEAL, Rosemiro Pereira; et. al. Curso de direito econômico-comunitário. Porto Alegre: Síntese, 2001.

21 FARIA, José Eduardo. O Direito na Economia Globalizada. São Paulo: Malheiros, 1999, p. 293. 
há listas de exceções de produtos e serviços que os Estados Membros adotam medidas protecionistas. Assim, serão verificados no próximo item os esforços mercosulinos em integrar seus membros para além da dinâmica econômica e comercial.

\section{NOVOS DESAFIOS PARA A INCLUSÃO DOS ASPECTOS PLURAIS DE PARTICIPAÇÃO CIDADÃ NO MERCOSUL}

Mesmo com embargos existentes em razão de posicionamentos protecionistas e a existência de muitos acordos bilaterais em face à feitura de acordos que tenham vigência para os cinco membros do bloco, tem-se que a situação atual do MERCOSUL não é estática em termos dos vários acordos e relações internacionais desenvolvidos intra e extra-bloco, pois aquele poderá expandir para o alto grau de integração, tornando-se uma comunidade de Estados com um mercado comum, caso haja a união política, social, econômica e cultural resguardados por um Direito da sua integração regional.

Sobre a formação difusa do Direito mercosulino, ou seja, realizada em meio às discussões existentes nos fóruns de debates e reuniões oficiais pelos órgãos do bloco, insta analisar a expansão da agenda temática do bloco, pois pode ser averiguada nas ações dos Estados junto aos órgãos de integração a formação de um arcabouço normativo comum a favor do desenvolvimento não somente econômico-comercial no bloco.

Partilha destas considerações Andrade ${ }^{22}$ :

(...) felizmente pode-se constar que o MERCOSUL está no bom caminho para o desenvolvimento. Ao acrescentar ao aspecto econômico o aspecto humano, o bloco mostra-se mais sábio que a OMC, pois possui a percepção de que o desenvolvimento pleno só pode ser atingido quando se leva em consideração a sorte das populações de seus Estados Partes (...) como quer o Tratado de Assunção.

O desenvolvimento social foi formalizado como compromisso do MERCOSUL na Carta de Buenos Aires, documento firmado em julho de 2000, entre MERCOSUL, Bolívia e Chile. Constam como metas da referida Carta, já em seu preâmbulo: o desenvolvimento econômico e a plena integração regional pelo viés da justiça social; e a busca pelo desenvolvimento em diversas áreas, não só econômica, pois esta, por si, não é suficiente para alcançar a melhoria na qualidade de vida, erradicar a pobreza e eliminar a discriminação e a exclusão social. Tais considerações possuem fundamento no princípio da coesão econômica

22 ANDRADE, Isabela Piacentini de. "MERCOSUL e desenvolvimento? Integração regional e desenvolvimento". In BARRAL, Welber e BACELLAR FILHO, Romeu Felipe (ed.). Florianópolis: Fundação Boiteux, 2007, p. 248. 
e social no Direito Comunitário, que consiste no auxílio aos Estados que estiverem em situação de dificuldades no desenvolvimento de suas potencialidades, e, portanto, a sua participação no bloco será feita de maneira flexível para adequá-lo a expansão regional ${ }^{23}$.

Tem-se essa iniciativa na criação dos Fundos de Convergência Estrutural do MERCOSUL (FOCEM) destinado a fazer tal flexibilização, visto que tais recursos financeiros do FOCEM serão repassados aos Estados mais limitados econômica e socialmente para que sejam investidos em programas de infraestrutura, pobreza, educação, saúde, competitividade empresarial e emprego ${ }^{24}$. Percebe-se aí o exaurimento dos princípios da solidariedade e cooperaçãoleal do Direito Comunitário.

Sobre os objetivos democráticos no MERCOSUL, foi assinado em julho de 1998 o Protocolo de Ushuaia sobre Compromisso Democrático no MERCOSUL, Bolívia e Chile, para a promoção e defesa da democracia no âmbito do bloco. Neste passo há, também, a ação conjunta entre o Parlasul e o Fórum Consultivo Econômico Social (FCES) que consiste na discussão de demandas econômicas e sociais em audiências públicas e debates semestrais junto a especialistas, assim, as assimetrias poderão se reduzir pela aproximação do diálogo entre os Membros tornando o processo de integração mais dinâmico e próximo da sociedade envolvida.

Para reforçar o conhecimento da atuação do Parlasul junto à sociedade mercosulina foi criado o Dia do MERCOSUL Cidadão, como proposta do Parlasul, como o marco das eleições parlamentares simultâneas do referido órgãos nos Estados Membros para aproximar as relações entre todos os envolvidos no processo de integração do bloco ${ }^{25}$.

Verifica-se que, para legitimar a atuação deste sistema político no bloco necessário se faz o fortalecimento na crença da sociedade mercosulina de que o Parlasul promoverá a aproximação entre as vontades expressas nas decisões dos governos envolvidos e os interesses da sociedade, assim tal reconhecimento a nível nacional e intergovernamental poderá favorecer a formação de uma identidade transnacional, visto que novos atores como grupos sociais e entes subnacionais poderão participar do processo de integração regional através de sua representaçãa ${ }^{26}$.

Assim, tem-se que em 1995 instituiu-se a Rede Mercocidades que representam o novo "desenho" de governança na América do Sul, contando atualmente por mais de 270 cidades de Argentina, Brasil,

23 CAMPOS, João Mota de e CAMPOS, João Luiz Mota de. Manual de Direito Comunitário - O Sistema Institucional. A Ordem Jurídica. O Ordenamento Económico da União Europeia. Coimbra: Coimbra, 2007.

24 YUSTE, Juan Carlos. "MERCOSUL social, matéria pendente”. Boletim Eletrônico do Programa MERCOSUL social e solidário. 2006, $\mathrm{n}^{\circ} 17$.

25 MEDEIROS, Marcelo de Almeida; LEITÃO, Natália; et al. "A questão da representação no MERCOSUL: os casos do Parlasul e do FCCR". Revista de Sociologia e Politica. 2010, vol 18, $\mathrm{n}^{\circ} 37$, p. 31-57.

26 Ibíd. 
Paraguai, Uruguai, Venezuela, Chile, Bolívia, Colômbia e Peru. Tal rede de interações atua como um instrumento de cooperação horizontal entre os governos subnacionais (estados e municípios) para que as demandas locais das sociedades alcancem os patamares dos benefícios e acesso à democratização nas decisões dos órgãos do MERCOSUL no desenvolvimento da sua integração regional.

A expansão das condições de emprego também é tema da agenda do bloco, são destacados os seguintes documentos e normas, como a Declaração dos Presidentes sobre a Erradicação do Trabalho Infantil nos Estados do MERCOSUL, assinada em 2002; a Estratégia MERCOSUL de crescimento do emprego, assinada em 2006; e a Resolução do GMC $\mathrm{n}^{\circ} 36$ de 2006, que estabeleceu o Plano Regional para a prevenção e erradicação do trabalho infantil no MERCOSUL.

No mesmo sentido, a defesa dos Direitos Humanos é um dos objetivos traçados pelos Estados do MERCOSUL para que a integração regional se expanda em outros aspectos tão ou mais importantes quanto o econômico. Sobre tais normas do bloco tem-se: a criação da Reunião de Altas Autoridades sobre Direitos Humanos do MERCOSUL, pela Decisão no 40 de 2004 do CMC; no Protocolo de Assunção sobre compromisso com a promoção e proteção dos direitos humanos do MERCOSUL, pela Decisão no 17 de 2005 do CMC; e para a erradicação da pobreza foi criada a Iniciativa de Assunção sobre a luta contra a pobreza extrema, assinada em julho de 2005.

A proteção ambiental internacional é firmada como compromisso dos Estados-membros pela Resolução no 10 de 1994 do GMC que traça as diretrizes básicas em matéria de política ambiental, além do AcordoQuadro sobre o Meio Ambiente do MERCOSUL, assinado em 21 de julho de 2001.

Em meio às diversas discussões e tentativas em se criar um novo código aduaneiro para tal região sul-americana, foi criado o novo Código Aduaneiro do MERCOSUL em Agosto de 2010, durante a Cúpula do MERCOSUL na cidade de San Juan, na Argentina, pela Decisão $\mathrm{n}^{\circ}$ 27/10 do CMC. Além da harmonização legislativa sobre as questões aduaneiras do bloco, o código foi criado para a extinção da dupla cobrança da TEC e criou-se um mecanismo que permite a distribuição de renda aduaneira entre os Estados integrantes do MERCOSUL e a interconexão eletrônica pela transmissão de dados entre as alfândegas.

Os diversos aspectos de atuação do MERCOSUL para promover seu desenvolvimento regional não se esgotam nos documentos e normas mencionados anteriormente, pois as atividades dos órgãos mercosulinos e de seus Estados Membros se dinamizaram ao longo desses vinte anos de bloco. Como explica Brum ${ }^{27}$, para a expansão dos

27 BRUM, Argemiro Jacob. O desenvolvimento econômico brasileiro. $21^{\text {a }}$ ed. Petrópolis: Vozes/ UNIJUI, 2000, p. 109. 
Estados fortalecedores do bloco é necessário visar o crescimento não somente comercial e econômico, veja-se:

(...) desenvolvimento, não é sinônimo de crescimento, nem se mede apenas pela renda média per capita. É a combinação de uma taxa elevada de investimento; de aumento da produção; de uma distribuição ampliada dos resultados do crescimento; da compreensão de que a economia entendida como gestão racional dos meios de produção está a serviço da integração social, da justiça coletiva e do bem estar individual; e de uma consciência cívica da responsabilidade coletiva em relação ao presente e futuro comum.

No mesmo sentido, tendo-se pela análise dos princípios do Direito Comunitário, observa-se a afirmação de Carneiro que, assim, vê a possibilidade de maior integração, conforme explica:

Entendemos que o efeito direto e a primazia da norma comunitária é o que conferem-lhe natureza supranacional,portanto, apesar os órgãos comunitários adotarem o mecanismo da intergovernabilidade, ou ainda, o fato de não haver transferência expressa de competências estatais para os órgãos de integração, não significa que não há instituições supranacionais no sistema do MERCOSUL, pois o que importa é que exista uma estrutura uma estrutura institucional metanacional e uma efetiva coordenação entre essas instituições e as instituições estatais para que se configure a supranacionalidade de um organismo comunitário ${ }^{28}$.

Tais questões estão em constante (re)formulação, não somente pelos tutelados do direito produzido no MERCOSÚL, bem como os diversos atores do cenário político mundial, pois os reflexos da atuação do bloco sul-americano inserem-se na dinâmica das relações econômica globais bem como de sua sociedade local.

\section{CONSIDERAÇÕES FINAIS}

O direito de integração econômica regional é formado por blocos integracionistas que estreitam suas relações para liberalização de comércio, serviços, pessoas e constituição de um direito comum ao bloco através da cooperação que se dá por etapas, que não são obrigatórias, pois cabe aos Estados estabelecerem quais os objetivos de integração econômica regional pretendem traçar para expandir suas potencialidades internas a nível regional e internacional.

Verificou-se no presente artigo que a União Europeia é uma das experiências avançadas de integração econômica regional, vez

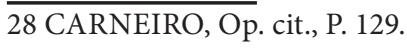


que se expandiu de mera cooperação para a unificação das relações econômicas, políticas, sociais e culturais, tendo como formalidade máxima de integração a institucionalização do direito comum. Este ramo do Direito, o Comunitário, é autônomo com princípios e normas próprias, pertencentes a um ordenamento comum, sendo regulamentado e coordenado por suas instituições, que são autônomas, a maioria de caráter supranacional, sendo capazes de constituir direitos e obrigações aos seus destinatários do bloco de integração econômica regional.

No continente Sul-americano foi instituído o bloco MERCOSUL pela necessidade dos países expandirem suas economias e melhorar as condições de vida de sua sociedade, sendo tal bloco formado num contexto de redemocratização dos países membros e necessidade de ter visibilidade e aumento da capacidade de negociação nas relações internacionais. Existe no MERCOSUL aplicação de princípios formadores do Direito Econômico Internacional que impulsiona a integração nos aspectos comerciais e financeiros, sendo os maiores desafios do bloco a uniformização da liberação dos produtos e serviços, pois há alguns embargos políticos impedem maior fluidez para as próximas fases da integração, motivo pelo qual o MERCOSUL se encontra na fase de União Aduaneira. Porém isso não impossibilita a instituição do direito regional comum a todos os países membros caso haja o estreitamento das cooperações nas demais áreas que foram incluídas na nova agenda do bloco, como cultura, tecnologia, meio ambiente, saúde, educação entre outras.

Os novos desafios do bloco relacionam-se com a manutenção das atividades de cunho social e democrático, pois se percebeu que o desenvolvimento institucional do MERCOSUL tem incorporado um conjunto de instituições participativas como grupos e subgrupos, reuniões especializadas, conferências que permitem a inclusão de novos atores nas discussões sobre questões sociais, culturais, políticas e econômicas da integração regional do bloco. Assim, tem-se que não só os agentes dos governos nacionais dos países membros tem "voz" dentro do bloco e, neste sentido, a participação é ampliada para os movimentos sociais, sindicatos, ONGs, partidos políticos, entes culturais e outros grupos da sociedade civil.

Sendo a democracia o regime de governo que possibilita a formação de espaços de diálogo e participação dos cidadãos nas decisões dos seus governantes. O pluralismo presente no referido regime se dá pela abertura aos diversos grupos da sociedade discutir as questões políticas que devem ir além do ato de voto eleitoral. A necessidade de pensar uma integração que seja minimamente democrática leva-se em consideração que as sociedades tuteladas pelas regras emanadas pelo bloco sejam representadas.

A pressão pela incorporação de demandas que valorizem maior grau de participação no MERCOSUL resultou na incorporação de novas 
instituições para aproximar governantes e governados para que possam se tornar políticas públicas a serem implementadas tanto em âmbito interno quanto regional. Para tanto, necessário se faz a mobilização social e trabalho de conscientização para que o MERCOSUL tenha visibilidade por parte de sua sociedade, tão importante quanto à que possui dos países do sistema internacional.

Através deste artigo não se pretendeu esgotar a pesquisa que se estende sobre o tema, tão atual e instigante, por outro lado, tal estudo pretende corresponder a uma colaboração para literatura que discute o Direito da Integração Regional e a promoção do diálogo entre Estados e os cidadãos do MERCOSUL.

\section{REFERÊNCIAS BIBLIOGRÁFICAS}

ALMEIDA, Paulo Roberto. Dilemas da soberania do MERCOSUL: a soberania. Rio de Janeiro: Renovar, 1999.

ANDRADE, Isabela Piacentini de. "MERCOSUL e desenvolvimento? Integração regional e desenvolvimento". In BARRAL, Welber e BACELLAR FILHO, Romeu Felipe (ed.). Florianópolis: Fundação Boiteux, 2007.

ANDRADE, Mayra Thaís. S. "O caráter supranacional do Conselho Mercado Comum - uma perspectiva de integração pelo Direito Comunitário". In III Encontro Nacional da Associação Brasileira de Relações Internacionais (ABRI), 2011. São Paulo: Governança Global e Novos Atores, 2011.

ANSELMO, José Roberto. “OMERCOSUL sob a ótica do direito comunitário”. Revista do Instituto de Pesquisas e Estudos. 2000, n² 29, p. 149-160.

AZEVEDO, Pedro Pontes. "A Lex Mercatoria e sua aplicação no ordenamento jurídico brasileiro". Revista Prima Facie. 2006, ano 5, n 9, p. 93-105.

BRUM, Argemiro Jacob. O desenvolvimento econômico brasileiro. $21^{\text {a }} \mathrm{ed}$. Petrópolis: Vozes/UNIJUI, 2000.

CAMPOS, João Mota de e CAMPOS, João Luiz Mota de. Manual de Direito Comunitário - O Sistema Institucional. A Ordem Jurídica. O Ordenamento Económico da União Europeia. Coimbra: Coimbra, 2007.

CARNEIRO, Cynthia Soares. Para Entender o Direito da integração regional. Belo Horizonte: Del Rey, 2007.

CARVALHO, José Antônio Marcondes de; BENJAMIN, Daniela. 
"Supranacionalidade ou efetividade: a dimensão jurídico-institucional do MERCOSUL". In: Seminário MERCOSUL 15 anos: Avaliação e perspectivas (março de 2006). São Paulo: s.n., 2006.

COSTA E SILVA, Danielle Cristine. "Soberania e MERCOSUL. [Dissertação de mestrado]. Pontifícia Universidade Católica de Minas Gerais. Belo Horizonte, 2003.

EVERTS, Philip. "Democracy and foreign policy”. In: CASTERMASHOLLEMANP, Monique; HOOF, Fried Van; SMITH, Jaqueline. The role of the nation-estate in the 21st century: human rights, international organizations and foreign policy. The Hague: Cambridge, 1998.

FARIA, Adriana Spagnol de. "Soberania popular e a supranacionalidade no MERCOSUL”. [Dissertação de mestrado]. Pontifícia Universidade Católica de Minas Gerais. Belo Horizonte, 2004.

FARIA, José Eduardo. O Direito na Economia Globalizada. São Paulo: Malheiros, 1999.

FERREIRA, Thiago José Milet Cavalcanti. "Efeito direto das normas comunitárias: Um ensaio sobre o futuro da experiência brasileira" [online]. Jus Navigandi. 2009, ano 13, $\mathrm{n}^{\circ} 2139$ [acesso em 02 dez. 2014]. Disponível em: $<$ http://jus.com.br/artigos/12807/efeito-direto-das-normas-comunitarias>

GUERRA, Sidney Cesar Silva. "Os desafios à integração regional no âmbito do MERCOSUL". Revista de Direito da UNIGRANRIO. 2009, vol 3, p. 1-26.

JO, Hee. Introdução ao Direito Internacional. $2^{\text {a }}$ ed. São Paulo: LTr, 2004.

LEAL, Rosemiro Pereira; et. al. Curso de direito econômico-comunitário. Porto Alegre: Síntese, 2001.

MAZZUOLI, Valério de Oliveira. Coletânea de Direito Internacional. Legislação do MERCOSUL. ${ }^{\mathrm{a}}$ ed. São Paulo: Revista dos Tribunais, 2009.

MEDEIROS, Marcelo de Almeida; LEITÃO, Natália; et al. "A questão da representação no MERCOSUL: os casos do Parlasul e do FCCR”. Revista de Sociologia e Política. 2010, vol 18, n³7, p. 31-57.

MERCOSUL. Protocolo Adicional ao Tratado de Assunção sobre estrutura institucional do MERCOSUL - Protocolo de Ouro Preto. 17 de dezembro de 1994 [acesso em 28 nov. 2014]. Disponível em: <http://www.sice.oas. org/trade/mrcsrp/ourop/ourop_p.asp\#Capítulo_XII_>

MERCOSUL. Protocolo de Ushuaia sobre o Compromisso Democrático no MERCOSUL, Bolívia e Chile [acesso em 28 nov. 2014]. Disponível em: <http:// 
www.mercosur.int/msweb/Normas/Tratado\%20e\%20Protocolos/1998_ PROTOCOLO\%20DE\%20USHUAIA-Compromiso\%20democr\%C3\%A1tico_ port.pdf>

MÜLLER, Vivian Cristina. "Direito comunitário: a função judicial no MERCOSUL" [online]. Jus Navigandi. 2004, ano 9, n 232 [acesso em 08 nov. 2014]. Disponível em: <http://jus.com.br/revista/texto/4873>

SILVA, Renata Cristina de Oliveira Alencar; SILVA, Osvaldo Alencar. "Supranacionalidade e integração: o caso MERCOSUL" [online]. Jus Navigandi. 2003, ano 7, $\mathrm{n}^{\circ} 64$ [acesso em 08 nov. 2014]. Disponível em: $<$ http://jus.com.br/artigos/3985/supranacionalidade-e-integracao/1>

SILVA, Roberto Luiz. Direito Econômico Internacional e Direito Comunitário. Belo Horizonte: Del Rey, 1995.

SILVA, Roberto Luiz. Direito Internacional Público. $4^{\text {a }}$ ed. Belo Horizonte, Del Rey, 2010.

SOARES, Mário. “Teoria geral da cidadania em suas expressões clássicas - Paradigma Greco-romano e medieval”. [Dissertação de mestrado]. Faculdade de Direito da Universidade Federal de Minas Gerais. Belo Horizonte, 1995.

VENTURA, Deisy F. L. "Os dilemas da institucionalização: um turning point para o MERCOSUL”. São Paulo em Perspectiva. 1995, vol 9, n 1, p. 75-79.

YUSTE, Juan Carlos. "MERCOSUL social, matéria pendente”. Boletim Eletrônico do Programa MERCOSUL social e solidário. 2006, $\mathrm{n}^{\circ} 17$. 